\title{
ACROMEGALY IN A GIRL OF 8 YEARS
}

\author{
BY \\ R. MCLAREN TODD \\ From the Department of Child Health, University of Liverpool
}

(RECEIVED FOR PUBLICATION JUNE 21, 1957)

Pierre Marie in 1886 first suggested the name acromegaly for a clinical condition associated with enlargement of the extremities ( $\alpha \dot{\alpha} \kappa \alpha)$ which he had observed in two women aged 37 and 54 years. Marie reviewed the literature and found records of five male patients (two of whom were brothers) with similar features; the earliest of these descriptions concerned a man of 39 years reported by Saucerotte (1772). Marie also discussed the differential diagnosis of acromegaly from myxoedema, Paget's disease of bone (osteitis deformans) and leontiasis ossea of Virchow.

Although Saucerotte's account is probably the earliest medical description of acromegaly, the condition was well known to ancient writers. For example, the height of Goliath of Gath (1 Samuel 17. 4) was 6 cubits and a span $\left(9 \frac{1}{2} \mathrm{ft}\right.$.) and the record suggests that he may have suffered from a pituitary tumour which caused bitemporal hemianopia and so he was unable to see the stone slung at him by David. It is also of interest that Goliath's son was a man of great stature (2 Samuel 22. 20) and that he had polydactyly (six fingers on each hand and six toes on each foot); Goliath's brother was also a giant and the staff of his spear was like a weaver's beam (2 Samuel 22. 19).

The first paper suggesting a relationship between acromegaly and the pituitary gland was that of Verga (1864) of Milan. He reported the necropsy findings of a woman of 59 years who began to develop evidence of acromegaly at the age of 35 years; the post-mortem examination revealed a tumour extending from the sella turcica and compressing the optic nerves.

Acromegaly is exceedingly rare and is especially uncommon in childhood. Atkinson (1931) reviewed the world literature from 1890 to 1929 and found 15 boys and 10 girls under the age of 15 years suffering from acromegaly; during the past 25 years a few cases have been reported (Schlesinger, 1931; Behrens and Barr, 1932; Seale, 1934 and 1935; Hurxthal, 1943). The only previous case recorded in the Archives of Disease in Childhood since this journal was first published in 1926 concerns a boy of 6 years who lived in Brno (Traub, 1939) and showed acromegalic gigantism associated with bony changes in the right hip, tarsal scaphoids, metatarsals and vertebral bodies.

\section{Case Report}

G.O. was born on August 23, 1947, after a normal pregnancy and delivery. She weighed $7 \frac{1}{2} \mathrm{lb}$. at birth and developed normally until the age of 5 years when she had a mild attack of whooping cough. After this illness her mother noticed that she tired easily and that she was putting on weight excessively. It was not until two years later that the symptoms became more obvious. She consulted her family doctor (Dr. W. Jones Morris) in July, 1954, when she was 6 years 11 months old because of persistent nasal catarrh and he observed the acromegalic features. Her height at this time was $54 \frac{1}{2}$ inches. Her general health was good, her appetite was rather excessive, but she did not complain of visual disturbances (she had worn glasses from the age of 3 years), headaches or vomiting. A study of family photographs suggests that acromegaly had been present for some years. A photograph of the patient with her elder sister and younger brother taken when she was 3 years old did not show the features of acromegaly (Fig. 1) but a photograph taken when her brother was 4 years old and she was $5 \frac{1}{2}$ years old shows the enlarged hands and abnormal facial appearance of acromegaly (Fig. 2).

She was admitted to Alder Hey Children's Hospital, Liverpool, in February, 1956, for further investigation.

On admission (aged $8 \frac{1}{2}$ years) she weighed $116 \mathrm{lb}$., her height was 60 inches (height-age of $12 \frac{1}{2}$ years) and head circumference was 22 in. She was a heavily-built, coarse-featured child, with black hair, bushy eyebrows and the typical features of acromegaly. There was slight but definite generalized pigmentation of the skin, and pigmentation was especially marked in the axillae, groins, areolae and umbilical area. There was no axillary hair and no breast enlargement, but a small amount of pubic hair. There were no abnormal signs in the heart or lungs, blood pressure was $125 / 75 \mathrm{~mm}$. Hg, and the abdomen was enlarged due to deposition of subcutaneous fat. Examination of the central nervous system, including optic fundi, was negative.

Table 1 records the measurements made of the patient, and of a girl one year older who was in the ward at the same time for investigation of 'dizzy spells'.

Further comparison is afforded by photographs of the hands (Fig. 3) and feet (Fig. 4), and by a full-length 


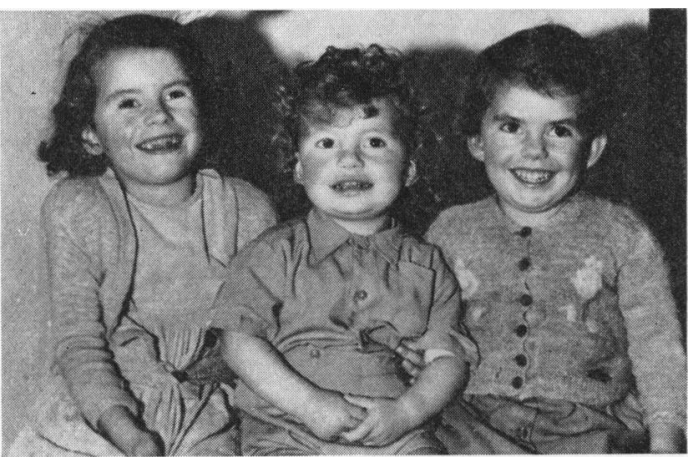

FIG. 1.

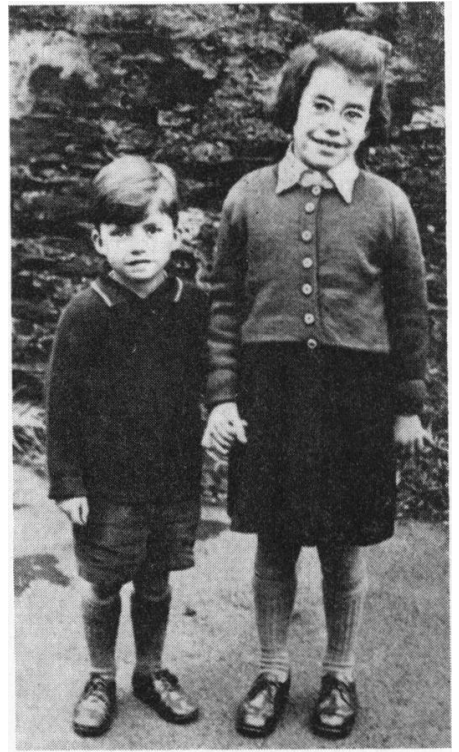

FIG. 2.

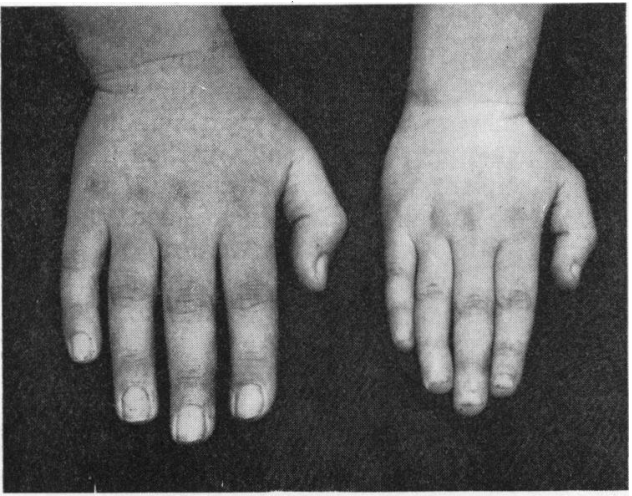

FIG. 3.

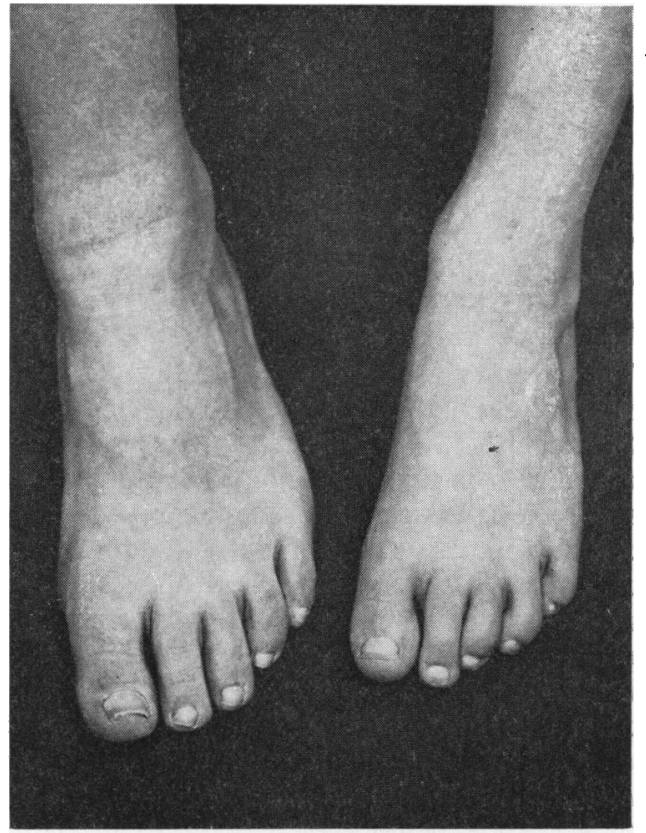

FIG. 4.

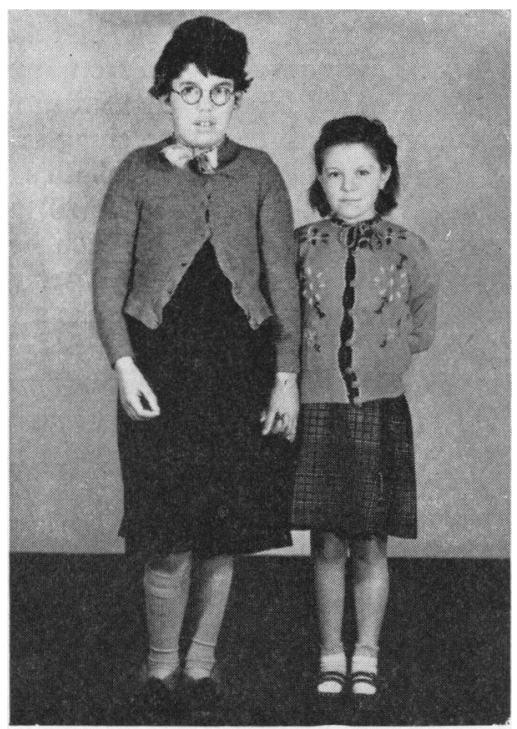

Fig. 5 .

FIG. 1.-Patient (extreme right) at age of 3 years with brother and sister.

Fig. 2.-Patient at age of $5 \frac{1}{2}$ years with brother.

Fig. 3.-Right hand of patient and control.

Fio. 4.-Left foot of patient and control.

Fig. 5.-Full-length photograph of patient and control. 
TABLE 1

MEASUREMENTS COMPARED WITH THOSE OF A CONTROL

\begin{tabular}{|c|c|c|}
\hline & Control & Patient \\
\hline 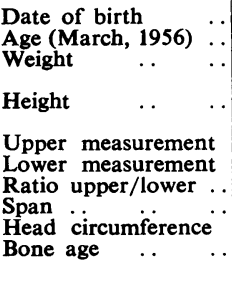 & $\begin{array}{l}23.6 .46 \\
9 \text { years } 9 \text { months } \\
67 \text { lb. } 4 \text { oz. ( } 50 \text { th per- } \\
\text { percentile) } \\
51 \frac{1}{2} \text { in. ( } 50 \text { th per- } \\
\text { centile) } \\
26 \text { in. (normal) } \\
25 \frac{1}{2} \text { in. (normal) } \\
50 \frac{1}{2} \text { in. (normal } 52 \text { ) } \\
21 \text { in. (normal) } \\
\text { Same as chronological } \\
\text { age }\end{array}$ & $\begin{array}{l}28.8 .47 \\
8 \text { years } 7 \text { months } \\
116 \text { lb. } 2 \text { oz. } \\
60 \text { in. (height age } \\
12 \frac{1}{2} \text { yr.) } \\
31 \frac{1}{2} \text { in. (normal 26) } \\
28 \frac{1}{2} \text { in. (normal 25) } \\
59 \text { in. (normal 50) } \\
22 \text { in. (normal 21) } \\
\text { Same as chronological } \\
\text { age }\end{array}$ \\
\hline
\end{tabular}

TABLE 2

MEASUREMENTS OF PATIENT'S FAMILY

\begin{tabular}{|c|c|c|}
\hline & Height & Weight \\
\hline $\begin{array}{lll}\text { Father } & \ldots & \\
\text { Mother } & \ldots & \\
\text { Sister (aged } & \text { i0 } & \text { yr.) } \\
\text { Brother (aged } & 7 & \text { yr.) }\end{array}$ & $\begin{array}{l}5 \mathrm{ft} .8 \mathrm{in} . \\
5 \mathrm{ft} .3 \mathrm{in} . \\
4 \mathrm{ft} .7 \mathrm{in} . \\
4 \mathrm{ft} .1 \mathrm{in} .\end{array}$ & 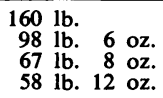 \\
\hline
\end{tabular}

photograph (Fig. 5). The height and weight of other members of the patient's family are recorded in Table 2 .
Investigations. Urine was of $p \mathrm{H} 5.5$ and specific gravity 1020 . No albumin, no reducing substances and nothing abnormal was seen in a centrifuged deposit.

Blood urea was $27 \mathrm{mg}$. \%.

A blood count gave $\mathrm{Hb} 78 \%(11 \cdot 5 \mathrm{~g} . \%)$, leucocytes 9,000 per c.mm. (normal differential count).

Serum protein was $6.8 \mathrm{~g} . \%$, serum calcium $5.0 \mathrm{mEq} / \mathrm{l}$., serum phosphorus $6.8 \mathrm{mg}$. $\%$, serum alkaline phosphatase $14 \mathrm{~K}-\mathrm{A}$ units $\%$, serum potassium $4 \mathrm{mEq} / \mathrm{l}$., serum cholesterol $190 \mathrm{mg}$. \%, alkali reserve $19 \mathrm{mEq} / \mathrm{l}$.

A glucose tolerance test gave the fasting blood sugar $100 \mathrm{mg}$. $\%$, and half an hour after $35 \mathrm{~g}$. glucose $130 \mathrm{mg}$. $\%$, one hour $130 \mathrm{mg}$. $\%$, two hours $140 \mathrm{mg}$. $\%$ and three hours $160 \mathrm{mg} . \%$.

An insulin tolerance test gave the fasting blood sugar $107 \mathrm{mg}$., 20 minutes after 6 units of insulin $85 \mathrm{mg}$. \%, 30 minutes $85 \mathrm{mg}$. \%, 45 minutes $112 \mathrm{mg}$. \%, one hour $95 \mathrm{mg} . \%$, two hours $110 \mathrm{mg}$. \%.

The total 17-ketosteroid content of a 24-hourly collection of urine was $2.8 \mathrm{mg}$. (average 0.3 to $1.99 \mathrm{mg}$.). The total 17 ketogenic steroids (corticosteroids) content of a 24-hourly collection of urine was $4 \cdot 22 \mathrm{mg}$. (average 0.3 to $1.99 \mathrm{mg}$.).

An eosinophil test before intramuscular injection of A.C.T.H. gave 238 eosinophils per c.mm., after one hour 241, two hours 155, three hours 113, four hours 113.

Radiographs of the wrists and elbows show a bone

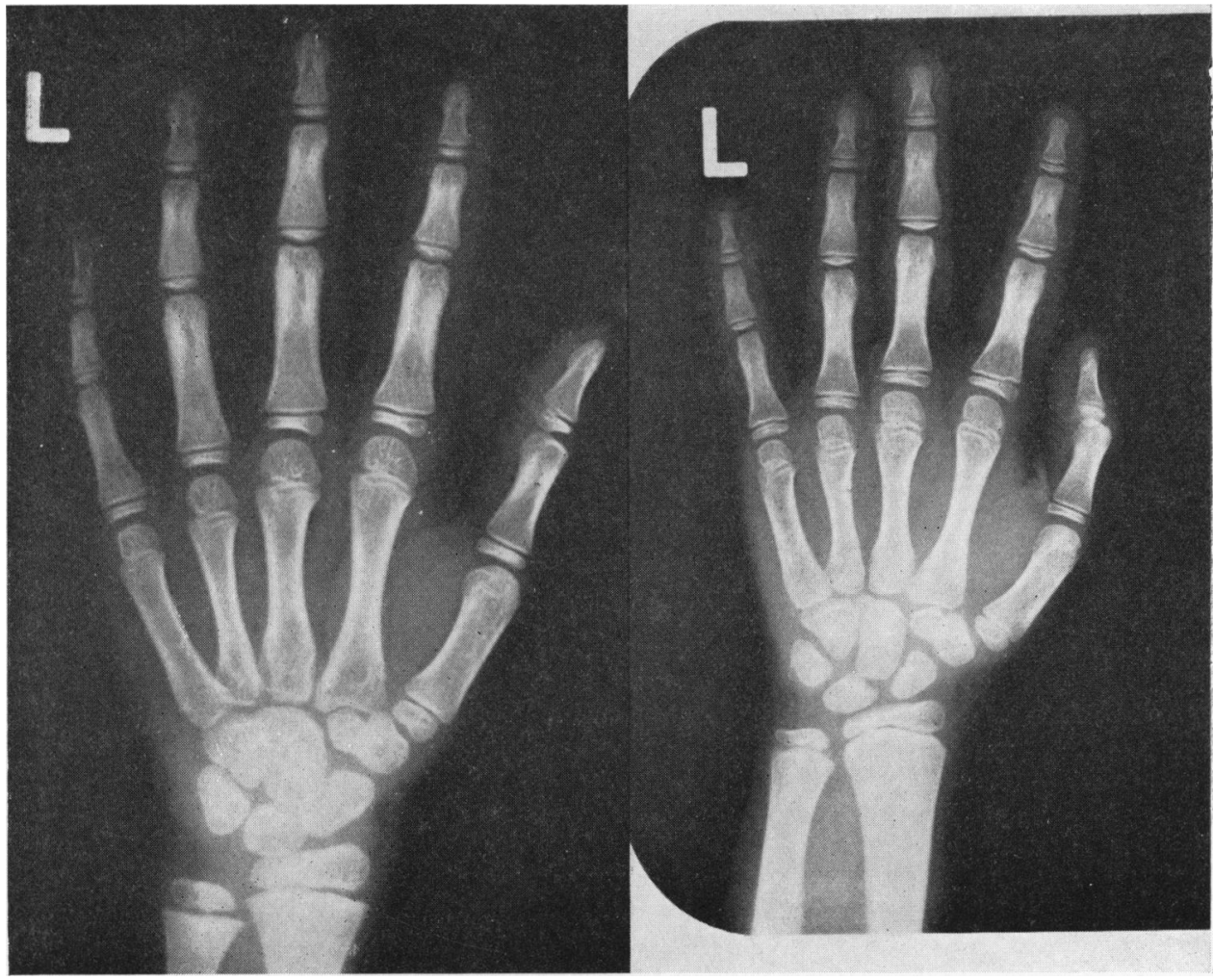

FIG. 6.-Radiograph of left wrist of patient and control. 
age of 8 to 9 years (Fig. 6). The sella turcica was larger and deeper than that of the control (Fig. 7). No destructive changes were shown and there was no evidence of intracranial calcification.

An intravenous pyelogram was normal.

At rest an E.E.G. (Fig. 8) showed an irregular 9 per second alpha rhythm, and a considerable amount of slow activity within theta and delta ranges. There was no significant change on hyperventilation or on photic stimulation. The slow activity was very prominent and the delta activity was outside the limits of normal for a child of this age (report by Dr. R. R. Hughes).

A urinary nitrogen excretion test was carried out over a period of two weeks. The patient excreted 4.5 g. $\mathrm{N}_{2}$ daily in urine, whereas a control excreted $7 \cdot 2$ g. per day.

The visual fields were

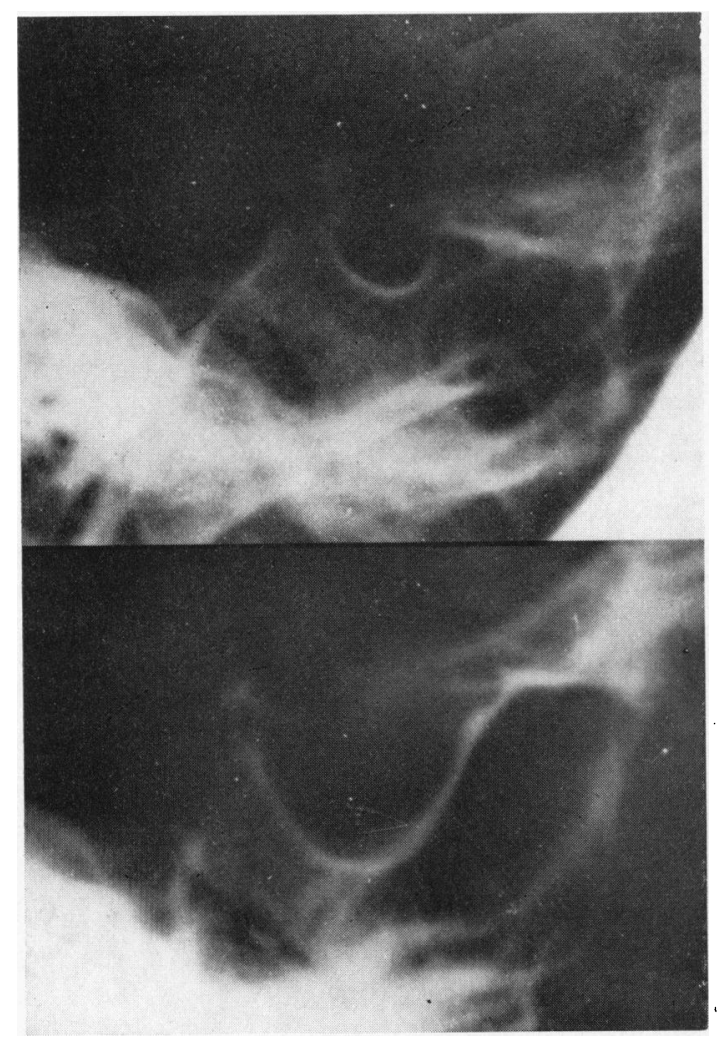

FIG. 7.-Radiographs of pituitary fossa of patient and control. entirely normal, and central colours also normal.

The patient was under observation in hospital for 11 weeks and during this period her height increased from 60 to $60 \frac{1}{2}$ in. and weight increased from 116 lb. $2 \mathrm{oz}$. to $125 \mathrm{lb} .4 \mathrm{oz}$. During this time the optic fundi remained normal, and she did not suffer from headache, vomiting or visual disturbance. She was seen, as an out-patient, by a radiotherapist (Dr. D. M. Fraser) who reported: 'I agree with you that acromegalic gigantism is the most probable diagnosis but I do not think that we should be justified in giving radiotherapy to the pituitary without more positive evidence of the presence of a tumour.'

In view of her continued growth and the embarrassment it caused her, particularly at school, it was decided to give oestrogens in an effort to promote epiphyseal fusion and thus prevent further excessive
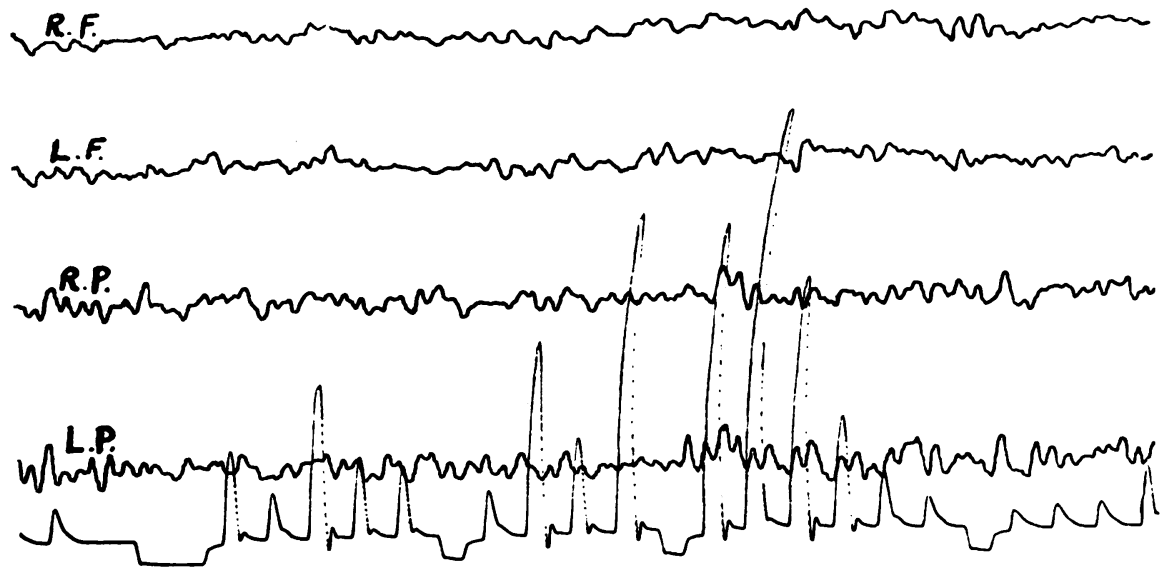

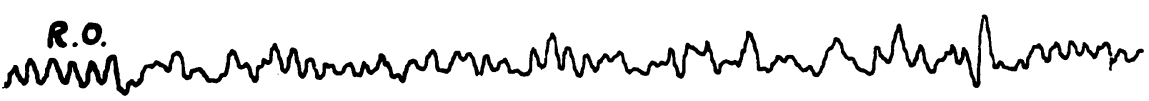

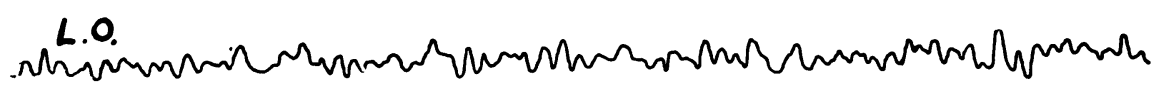




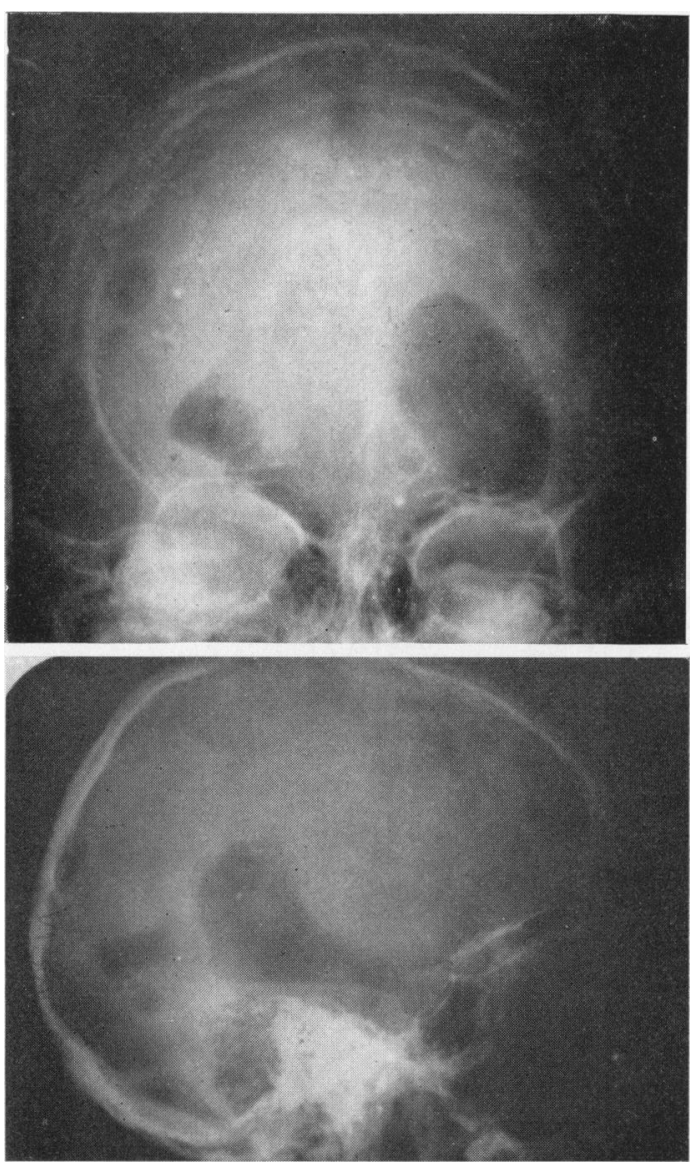

FIGs. 9A and 9B.-Ventriculogram.

growth of the long bones. She received stilboestrol, $1 \mathrm{mg}$. daily, for three weeks, and then $1 \mathrm{mg}$. twice daily for three weeks. It was discontinued because of vomiting and severe headaches. Menstrual bleeding started one week after stilboestrol was stopped and bleeding continued for four days. She was readmitted to hospital on September 24, 1956 , because of increasingly severe headaches in the frontal and occipital regions, and vomiting several times daily.

The fundi were examined and bilateral papilloedema of about 3 dioptres swelling was observed. She was seen by Mr. Hannah (neurosurgeon) who agreed to relieve the raised intracranial tension surgically. A ventriculogram (Fig. 9A and 9B) showed evidence of a large suprasellar lesion which was partially blocking the ventricles. It was felt that a direct approach to the tumour was fraught with danger and it was decided to perform a Torkildsen's operation, making a short circuit between the lateral ventricle and the cisterna magna. The symptoms were relieved after operation and she was then given $x$-ray therapy over a period of four weeks to a tumour dose of 3,000 roentgen units. At a follow-up examination on
February 18, 1957, her general condition was satisfactory, she had not suffered from headaches, the visual fields were normal, and the papilloedema had completely subsided. The acromegalic features were not more marked.

\section{Discussion}

The diagnosis of pituitary gigantism is founded upon the clinical and radiological manifestations Talbot, Sobel, McArthur and Crawford (1952) have described the main clinical features as follows: (a) Rapid growth of the skeleton and supporting mesenchymal structures; (b) no acceleration of skeletal maturation; (c) usually no gross evidence of hyperthyroidism, hyperadrenocorticism or hypergonadism; (d) occasionally signs of an expanding lesion in the region of the pituitary.

(a) The patient reported in this paper shows these clinical features. Growth has been rapid from a out 5 years of age, and her height was $54 \frac{1}{2}$ in. at the uge of 7 years (height age of $10 \frac{1}{2}$ years) and 60 in. at $8 \frac{1}{2}$ years (height age of $12 \frac{1}{2}$ years). (b) The excessive growth is due to excessive production of pituitary growth hormone and this hormone does not cause early skeletal maturation or closure of epiphyses. The bone age of this patient was the same as her chronological age. (c) There was no clinical evidence of overactivity of the thyroid, adrenal or sex glands and the following investigations support the clinical findings: serum cholesterol normal, excretion of 17 ketosteroids only slightly above the average normal, response to A.C.T.H. normal, blood electrolytes normal. (d) The patient also showed clinical evidence of an expanding intracranial lesion (headache, vomiting, papilloedema) and this was confirmed by encephalography.

In addition to these main clinical features, the diagnosis is supported by haematological and radiological abnormalities. The glucose tolerance curve was of the diabetic type and the patient showed insulin resistance. There was also evidence from balance studies of retention of nitrogen (pituitary growth hormone increases the utilization of amino-acids for synthesis of tissue proteins, causing thereby retention of nitrogen). Wilkins (1950) states that the finding of a high serum phosphorus level of the order of 5 to $6 \mathrm{mg}$. \% may be valuable in confirming the diagnosis of hyperpituitarism and in this patient the serum phosphorus level was $6.8 \mathrm{mg} . \%$. Patients with pituitary gigantism sometimes show radiological changes of the terminal phalanges, cancellous tufts develop, and small spaces of bone may be observed. This patient showed cancellous tufting of some of the terminal phalanges. Seale (1935) reported an eosinophilia 
(12 to $16 \%$ ) in an acromegalic boy of 12 years but could find no reports of similar blood changes; the blood count of our patient showed no increase of eosinophil cells.

The treatment recommended for pituitary gigantism will vary with the severity of the disease but involves either surgery, irradiation or hormones.

Surgical removal of an eosinophil tumour of the pituitary gland is a difficult procedure and the mortality rate is high. Surgical treatment is usually restricted, as in this patient, to relief of intracranial tension by a short circuit operation, especially when vision is threatened. Irradiation of the sella turcica is the most usual form of therapy and is often carried out (as in this patient) after relief of intracranial tension by surgical means. There is a risk of damage to other pituitary cells, and after radiotherapy symptoms of diabetes insipidus may be observed.

The use of hormones to hasten bone maturation and epiphyseal fusion seems a rational form of therapy. Testosterone or stilboestrol hasten epiphyseal fusion and also inhibit the secretion of pituitary hormones. This patient received stilboestrol for a short period only but there was some radiological evidence to suggest that bone maturation was hastened even by such a short course of therapy. Other hormones, e.g., posterior pituitary extract, may also be required to control the symptoms of diabetes insipidus which may develop either because of the pressure of a rapidly growing eosinophil tumour on the posterior pituitary gland, or after irradiation of the sella turcica.

\section{Summary}

The clinical features and results of investigations of a girl of 8 years suffering from acromegaly are recorded.

The diagnosis and treatment of this endocrine disorder are discussed.

\section{REFERENCES}

Atkinson, F. R. B. (1931). Brit. J. Child. Dis., 28, 121.

Behrens, L. H. and Barr, D. P. (1932). Endocrinology, 16, 120.

Hurxthal, L. M. (1943). J. clin. Endocr., 3, 12.

Marie, P. (1886). Rev. Medecine, 6, 297.

Saucerotte,(1772). See Weinberg, S. J. (1931). Ann. med. Hist., n.s., 3,650 .

Schlesinger, B. (1931). Proc. roy. Soc. Med., 24, 1352.

Seale, E. A. (1934). S. Afr. med. J., 8, 371.

(1935). Ibid., 9, 295.

Talbot, N. B., Sobel, E. H., McArthur, J. W. and Crawford, J. D. (1952). Functional Endocrinology from Birth through Adolescence. Cambridge. Mass.

Traub, E. (1939). Arch. Dis. Childh., 14, 203.

Verga, A. (1864). See Weinberg, S. J. (1931). Ann. med. Hist., n.s., 3, 650 .

Wilkins, L. (1950). The Diagnosis and Treatment of Endocrine Disorders in Childhood and Adolescence, Springfield, Illinois. 